\title{
Transfer of response bias by injection of brain homogenates: A replication
}

ARNOLD M. GOLUB ${ }^{1}$ AND JAMES V. MCCONNELL, MENTAL HEALTH RESEARCH INSTITUTE, THE UNIVERSITY OF MICHIGAN, Ann Arbor, Mich. 48104

$A$ group of rats was trained to bar press under a CRF schedule. $A$ secund group served to control for the effects of handling and stimulation. Homogenates prepared from $t . e$ brains of these animals were injected into untrained recipient animals. These recipients were subsequently tested for bar-pressing rates and food magazine entries. Animals receiving "conditioned" homogenate made reliably more bar presses and magazine entries than did animals injected with "untrained" homogenate.

A number of investigators have reported transfer of response bias from one organism to another by injection of brain homogenates or extracts. These reports have generated considerable controversy, and to a large extent this controversy has focused upon the apparent inability of many laboratories to successfully replicate the original reports of the transfer phenomenon. This failure of replication has led some investigators to suggest that the effect is artifactual in nature. Recent evidence, however, indicates that the effect does reliably occur. Successful replications have been reported by each of the original investigators (Jacobson, Babich, Bubash, \& Jacobson, 1965; Nissen, Røigaard-Petersen, \& Fjerdingstad, 1965; Reinis, 1966; Ungar \& Oceguera-Navarro, 1966), and a number of other researchers have reported positive results with different paradigms (Jacobson, 1967).

Clearly, the substantial number of positive reports casts doubt upon the artifactual nature of the effect. Nevertheless, statistical reliability and experimental reproducibility are quite different. if the effect is to be treated experimentally, it must be replicable in independent laboratories, and while it has become apparent that the phenomenon is reproducible in the laboratories of the original investigators, it has also become obvious that some laboratories experience little success in attempts at replication.

McConnell (1967) has pointed out a number of behavioral biochemical, and physiological parameters which should be controlled in memory transfer research. In an area in which a number of parameters appear critical, but are usually incompletely specified by the original investigators, failure to replicate is understandable.

With the previous considerations in mind, we undertook to replicate, as exactly as possible, a transfer paradigm which has been successfully used a number of times in the laboratory of the original investigators at Texas Christian University (Dyal, Golub, \& Marrone, 1967; Dyal \& Golub, in press). This paradigm consists of training donor animals to emit bar presses under a CRF schedule. These animals, along with their controls, are then sacrificed, their brains are removed, and brain homogenates are prepared. This preparation is subsequently injected into recipient animals which are tested for the bar-pressing response.

Method. The Ss were 36 naive, male, Sprague-Dawley rats, $100-150$ days old at the beginning of the experiment. The apparatus consisted of two Grason-Stadler rat chambers (Model E3125A). The single bar was moved to the side of the chamber opposite the food cup and centered 1 in. from the Plexiglas door. A photoelectric beam was passed across the entrance to the food magazine so that each time $S$ stuck its nose at least $1 \mathrm{~cm}$ into the food magazine, the event was cumulated on counters. Bar presses were also cumulated on counters. During the recipient testing session, an Esterline-Angus pen recorder was used to record both bar presses (BP) and food magazine entries (ME), thereby permitting evaluation of the temporal distribution of these responses throughout the session.

Twenty-four of the $\mathrm{Ss}$ served as donor animals and were assigned at random either to an experimental $(\mathrm{N}=12)$ or a control $(\mathrm{N}=12)$ group. The remaining 12 Ss were randomly assigned to two recipient groups of $N=6$ each. Two experimental donor Ss failed to acquire the bar-press response by the third day of training and, together with their donor controls, were eliminated from the study. Two recipient $S s$ were therefore also eliminated from the study. Six days prior to training, donor animals were placed on a 22.5-h food deprivation schedule. The experimental donor group received eight days of bar-press training in which each bar press was reinforced by a 45 mg Noyes food pellet delivered into the food magazine. Each time the food delivery mechanism was operated, the photoelectric light source in the magazine momentarily dimmed. In effect, this combined "light-click" stimulus served to signal the availability of food to the donor Ss. The eight days of bar-press training were followed by three days of extinction in which responses were not reinforced with food, followed in turn by three days of response reacquisition. The donor control group was used to control for the effects of experience and the light-click stimulation in the apparatus. Control Ss were yoked to experimental Ss such that each time the experimental $S$ emitted a bar press, the light-click stimulation also occurred in the control chamber; however, control Ss never received food in the chamber (bar presses by control Ss were recorded, but did not activate the food delivery mechanism). All donor training sessions were $30 \mathrm{~min}$ in duration, seven days a week.

Within $15 \mathrm{~min}$ following the final training session, donor Ss were sacrificed with ether. The brain, excluding the olfactory bulbs and cerebellum, was removed and stored in a tissue grinder in dry ice. Group homogenates were prepared and coded. ${ }^{2}$ Homogenization was performed by adding $1 \mathrm{cc}$ normal saline per brain and homogenizing in an ice bath. Recipient Ss were lightly etherized and injected intraperitoneally with $3.2 \mathrm{cc}$ of the homogenate through a 1 in., $20 \mathrm{~g}$ needle. All injections were performed "blind."

The recipient Ss had been on a 23 -h food deprivation schedule beginning six days prior to injection and were $23 \mathrm{~h}$ deprived at time of injection. They were $48-54 \mathrm{~h}$ deprived at the time of the test.

Testing was carried out in two consecutive 30 -min periods, using a double blind procedure. ${ }^{3}$ During the initial $30 \mathrm{~min}$, the bar was removed and the light-click stimulus presented every $60 \mathrm{sec}$. The number and temporal distribution of MEs during this session were recorded. At the end of this period, $\mathrm{S}$ was remoyed from the chamber, the bar was reinserted, and $\mathrm{S}$ was given a second 30-min test for bar pressing under a CRF schedule.

Results. During the first 30-min session, the mean number of MEs was 72.2 and 122.6 for Ss receiving homogenate from the control and experimental groups, respectively. These data, although in the direction predicted by the transfer hypothesis, were not reliably different. The number of MEs made during the $15 \mathrm{sec}$ immediately following each presentation of the light-click stimulus was then calculated for each $\mathrm{S}$. These values were used to determine what proportion of its total number of responses a $S$ made during these periods. Application of the $U$ test to these ranked data yielded a statistically reliable $U$ value $(U=4, p=$ .048 ).

During the second $30 \mathrm{~min}$, the mean number of bar presses made by animals receiving homogenate from experimental Ss was 14.2; the comparable value for $S$ s receiving homogenate from control Ss was 5. Application of the $U$ test to these data resulted in a significant $p$ value $(U=3, p=.028)$. The number of MEs during this period was 419.6 and 166 for experimental and control injected recipients, respectively. These ranked data were submitted to a $U$ test and the resulting statistic was highly reliable $(U=1, p=$ .008 ).

Discussion. The results of this replication provide additional support for the validity of a "transfer of training" effect by injection of material from the brains of trained animals. Inasmuch as there was no reliable difference between the recipient groups on the total number of MEs made during the initial 30-min session, the effect is presumably not attributable to a general elevation of ongoing activity, although such activity is probably in part responsible for the effect. Rather, our results suggest that the behavior of recipient animals injected with "trained" homogenate was under control of the discriminative stimulus (the light-click). Furthermore, since animals injected with material from donors receiving the same stimulation and experience as that of experimental donors, but given no opportunity to develop an association between these events and reinforcement, did not show the effect, 
a sensitization interpretation presumably is not applicable to these data. We must therefore conclude that the effect is statistically reliable, experimentally reproducible, and that it involves a high degree of specificity.

"Specificity" and "learning" are different terms, and no implication about the latter should be made from the former. "Specificity" implies that the effect is stimulus-specific, response-specific, or both. That is, injection of "trained" material may either increase the probability that the animal will attend to a particular stimulus configuration, or it may increase the probability of a particular response, such as bar pressing. In order to demonstrate "transfer of training," one must establish that an association exists between such stimulus and response events.

Although our data do not unequivocally indicate that a "transfer of training" (learning) effect is responsible for these results, they do suggest that the effect is highly specific and that this specificity probably involves both stimulus and response components. These data thus support the growing number of reports of "transfer of training" in the experimental literature. Further experiments are presently being performed in our laboratory to establish exactly what kinds of information can be transferred from one animal to another by injection of "conditioned" brain material.

We also believe that carefully controlled replications of the majority of the "transfer of training" reports will yield results that are essentially similar to those reported by the original investigators, and we are currently attempting to replicate some of these. In view of the literature in which attempted replications have yielded negative results (Jacobson, 1967), it is of the utmost importance that in future attempts to replicate, the Es minimize discrepancies between the original work and their replication: inadvertent changes in procedure or neglect of seemingly insignificant variables can result in important consequences. Research in which such changes have either consciously or unwittingly been made does not constitute a legitimate replication.

It has been our experience, as well as that of other laboratories, that the use of Es having little or no previous experience in training rats will lead almost uniformly to negative results with the majority of the transfer paradigms presently available. Thus, we believe it is doubtful that a single attempt at replication, performed by Es having little experience in training rats, will yield positive results. On the other hand, we feel that a series of attempts to replicate, in which care is taken to minimize discrepancies between the replication and the original research, will usually yield positive results.

\section{REFERENCES}

DYAL, J. A., GOLUB, A. M., \& MARRONE, R. L. Transfer effects of intraperitoneal injection of brain homogenates. Nature, 1967, 214, 720-721.

DYAL, J. A., \& GOLUB, A. M. Further positive transfer effects obtained through injections of brain homogenates. Psychon. Sci., 1968, 11, 13.14.

JACOBSON, A. L. A bibliography on "chemical transfer of training." J. biol. Psychol., 1967, 9(2), 52-55.

JACOBSON, A. L., BABICH, F. R., BUBASH, S., \& JACOBSON, ANN. Differential approach tendencies produced by injection of ribonucleic acid from trained rats. Science, 1965, 150, 636-637.

McCONNELL, J. V. Factors affecting the "transfer of training" effect in rats. J. biol. Psychol, 1967, 9(1), 40-48.

NISSEN, Th., RழIGAARD-PETERSEN, H. H., \& FJERDINGSTAD, E. J. Effect of ribonucleic acid (RNA) extracted from the brain of trained animals on learning in rats: II. The dependence of the RNA-effect on training conditions prior to RNA extraction. Scand. J. Psychol., 1965, 6, 265-272.

REINIS, S. Influence of brain homogenate injection on the speed of the formation of alimentary conditioned reflex in rats. Worm Runner's Digest, $1966,8,7-24$.

UNGAR, G., \& OCEGUERA-NAVARRO, C. Transfer of habituation by material extracted from brain. Nature, 1965, 207, 301-302.

\section{NOTES}

1. Post-doctoral fellow, Mental Health Research Institute, The University of Michigan.

2. The authors wish to thank Frank $R$. Masiarz for his assistance in homogenizing and coding the preparation.

3. The authors wish to thank Harold T. Salive and Mrs. Barbara Salive for their assistance in testing the recipient animals. 